\title{
ESTUDO POPULACIONAL DO CAMARÃO-ROSA PENAEUS PAULENSIS PÉREZ FARFANTE (NATANTIA, PENAEIDAE) NA LAGOA DA CONCEIÇÃO, SANTA CATARINA, BRASIL
}

\author{
Joaquim Olinto Branco ${ }^{1,2}$ \\ José Roberto Verani ${ }^{3}$
}

\begin{abstract}
Populational Study of the PINK-Shrimp Penaeus PaUlensis Pérez Farfante (Natantia, Penaeidae) in the Conceição Lake, Florianópolis, Santa CATARINA, BRAZIL. In the time period between May/92 to April/93, 2693 (1243 males and 1450 females) specimens of Penaeus paulensis Pérez Farfante, 1967 were collected. The shrimps were captured by night using a hand net in areas between 30 to 150 $\mathrm{cm}$ deep. The abundance of $P$. paulensis is regulated mainly by the temperature, the summer being the season of greater profusion. The major recruiting period takes place in the Spring with shrimps measuring between 1,0 to $3,0 \mathrm{~cm}$ and approximately 2,0 months old. The population reaches the pre-adult in the Fall-Winter period with average length between $8,8 \mathrm{~cm}$ (females) and 9,3 cm (males). The migration to the ocean occurs during the Winter. The artisanal fishing in the Conceição Lake is predatory, acting upon the young and pre-adult shrimps, which may jeopardize the marine reproducer stock.

KEY WORDS. Penaeus paulensis, populational structure, growth, migration, Conceição Lake
\end{abstract}

Penaeus paulensis Pérez Farfante, 1967 ocorre no litoral brasileiro, do Rio de Janeiro até o Rio Grande do Sul; Uruguai e nordeste da Argentina (PÉREZ FARFANTE 1969; HOLTHUIS 1980).

É a espécie mais importante do gênero Penaeus Fabricius, 1798 na região Sudeste-Sul, portanto, a mais estudada. Os camarões dessa espécie apresentam ciclo de vida que segue o padrão do gênero.

A reprodução ocorre em mar aberto, entre 40 a 100 metros de profundidade durante o ano todo. As pós-larvas penetram nos estuários onde ocorre o crescimento. A migração dos juvenis e pré-adultos para o mar ocorre entre os meses de fevereiro a maio (D’INCAO 1991). A fecundidade média por desova em laboratório variou entre 250.000 a 570.000 ovos e com desenvolvimento larval completo em 42 a 46 dias, à temperatura de $24,0^{\circ} \mathrm{C}$ a $26,0^{\circ} \mathrm{C}$ (IWAI 1978 in D'INCAO 1991).

1) Faculdade de Ciências do Mar, Universidade do Vale do Itajaí. Caixa Postal $360,88301-970$ Itajaí, Santa Catarina, Brasil.

2) Núcleo de Estudos do Mar, Centro de Ciências Biológicas, Universidade Federal de Santa Catarina. Florianópolis, Santa Catarina, Brasil.

3) Universidade Federal de São Carlos. Caixa Postal 676, 13565-905 São Carlos, São Paulo, Brasil. 
A principal área de pesca de $P$. paulensis no litoral brasileiro estende-se de Santos (São Paulo) a Torres (Rio Grande do Sul) (IWAI 1973). Para ZENKER \& AGNES (1977) existem duas zonas de alta produção pesqueira, a mais importante, ocorre em frente ao estado de Santa Catarina, e a outra entre Santos e a Ilha de São Sebastião (São Paulo). No estuário da Lagoa dos Patos (Rio Grande do sul), a espécie ocorre o ano todo, sendo que nos meses de dezembro a maio registram-se as maiores abundâncias (D'INCAO 1991).

Embora $P$. paulensis seja um recurso intensamente explorado no litoral catarinense, existem poucas informações sobre o seu ciclo de vida (NASCIMENTO et al. 1985). Entretanto, a análise dos dados oriundos dos desembarques da frota artesanal e industrial tem contribuído para a avaliação do estoque de camarão-rosa da região Sudeste-Sul (VALENTINI et al. 1991).

Devido à carência de informações e a intensa exploração dos penaeideos da Lagoa da Conceição, este trabalho tem como objetivo fornecer informações básicas sobre aspectos do ciclo de vida de $P$. paulensis, contribuindo para a administração e preservação desse importante recurso.

\section{MATERIAL E MÉTODOS}

Durante o período de maio/92 a abril/93, 2693 exemplares de $P$. paulensis (1243 machos e 1450 fêmeas) foram coletados mensalmente na Lagoa da Concei-

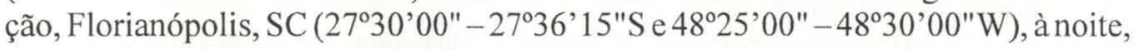
em três áreas de amostragens (Fig. 1). Os camarões foram coletados em profundidades de 30 a $150 \mathrm{~cm}$, sendo empregado um esforço de pesca de 30 minutos, cobrindo uma área aproximada de $100 \mathrm{~m}^{2}$ com auxílio de rede-de-mão (bernunça) (GAMBA et al. 1993). Um farol de automóvel preso em capacete de plástico conectado a bateria protegida em caixa de isopor de 100 litros foi usado como fonte luminosa. Paralelamente, as coletas foram registrados a temperatura e salinidade da água de superfície.

Para cada exemplar foram registrados o estádio de maturação (juvenil, pré-adulto) conforme PÉREZ FARFANTE (1970), sexo, comprimento total (Lt), comprimento da carapaça (Lc) em centímetros e peso total (Wt) em gramas.

O teste do $x^{2}$ com nivel de significância de $5 \%$ e n-1 graus de liberdade (n $=2$ ) foi aplicado para verificar a possível diferença entre os sexos em cada mês por estação do ano. A relação peso/comprimento total foi estimada para machos e fêmeas separadamente conforme SANTOS (1978). A relação comprimento da carapaça/comprimento total foi obtida graficamente para machos e fêmeas, através da dispersão dos pontos empíricos e analiticamente pela expressão: $\mathbf{L c}=\mathbf{B}$. Lt, onde "B" é a constante da relação linear.

O tamanho de pré-adulto ( $\mathrm{Lt}_{\mathrm{pa}}$ ) adotado neste trabalho, corresponde a freqüência onde $50 \%$ dos exemplares apresentam o petasma unido, nos machos e o télico completamente desenvolvido nas fêmeas (PÉREZ FARFANTE 1970); foi estimado, graficamente, de acordo com a metodologia recomendada para determinar o tamanho de primeira maturação (VAZZOLER 1981). 


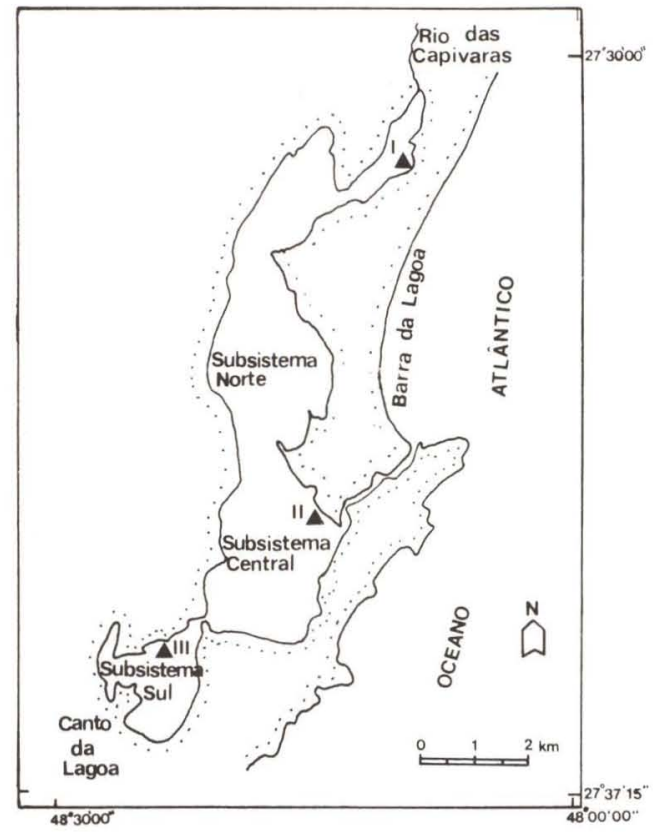

Fig. 1. Lagoa da Conceição. Mapa indicando as áreas de coleta.

A curva de crescimento em comprimento total foi estabelecida pelo método da distribuição de freqüência para sexos separados, bimestralmente (SANTOS 1978). A expressão de BERTALANFFY (1938) foi adaptada para $P$. paulensis resultando: $\mathrm{Lt}=\mathrm{L} \infty\left[1-\mathrm{e}^{-\mathrm{k}(\mathrm{t}-\mathrm{t} 0)}\right]$, onde: "Lt" é o comprimento total na idade $\mathrm{t}$; "L $\infty$ " é o comprimento assintótico; "e" é a base dos logaritmos neperianos; $\mathrm{k}$ é a constante relacionada com a taxa de crescimento; t0 parâmetro relacionado com comprimento ao nascer; $\mathrm{t}$ é a idade considerada.

A validade da expressão de Bertalanffy foi testada, previamente, com a aplicação da transformação de Ford-Walford (WALFORD 1946) e os parâmetros estimados conforme SANTOS (1978). Para $P$. paulensis, cujo comprimento total é desprezível ao nascer, assume-se que t0 seja igual a zero.

A curva de crescimento em peso, foi obtida pelo método dedutivo (SANTOS 1978), após o conhecimento da relação peso/comprimento total para machos e fêmeas, resultando na expressão: $\mathbf{W t}=\mathbf{W} \infty\left[1-\mathrm{e}^{-\mathrm{k}(\mathrm{t}-\mathrm{t} 0)}\right]^{\theta}$, onde: "Wt" é o peso na idade $t$; "Wo" é o peso assintótico e " $\theta$ " é a constante, relacionada com o crescimento da espécie da relação peso/comprimento total.

\section{RESULTADOS E DISCUSSÃO}

Os registros de temperatura da água de superfície da Lagoa da Conceição, durante o período de amostragem, demonstram que as áreas Norte, Central e Sul apresentam valores equivalentes, permitindo uma análise em conjunto. Assim, a temperatura média da água de superfície variou entre $16,2^{\circ} \mathrm{C}$ (julho/92) e $26,7^{\circ} \mathrm{C}$ 
(novembro/92) (Fig. 2). Nos meses de dezembro/92 a abril/93 foram registradas temperaturas médias entre 17,2 a $18,5^{\circ} \mathrm{C}$, consideradas baixas se comparadas ao padrão sazonal característico da Lagoa da Conceição.
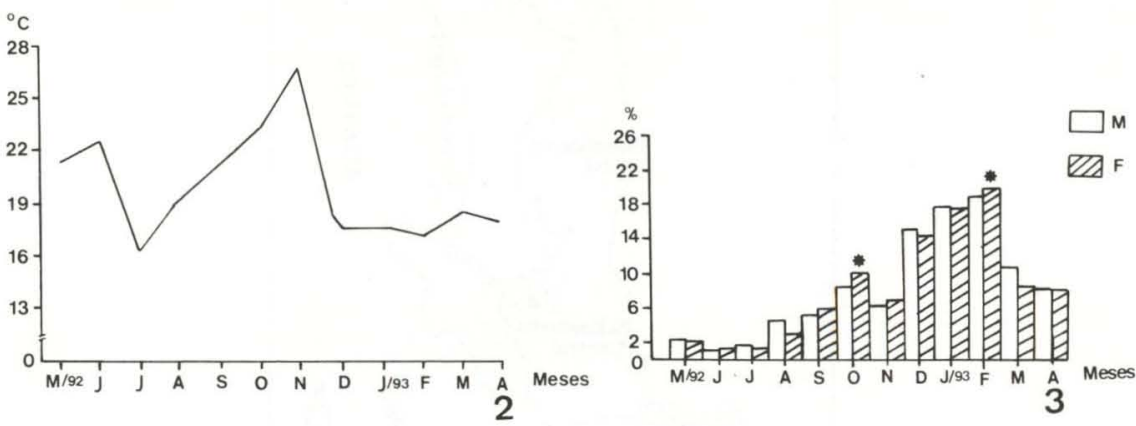

Figs 2-3. (2) Flutuação anual da temperatura média $\left({ }^{\circ} \mathrm{C}\right)$ da água de superficie da Lagoa da Conceição; (3) Penaeus paulensis. Distribuição mensal de freqüência de machos e fêmeas na Lagoa da Conceiçăo. O asterisco indica diferença singnificativa $p \leq 0,05$ a favor de um dos sexos.

A flutuação da salinidade da água de superfície apresentou um padrão com valores mais elevados na área Central seguida do Norte e Sul. A maior média mensal $(32,5 \%$ ) foi registrada em outubro/92 na área Central, e as menores $(17,0 \%) \mathrm{em}$ abril/92 e fevereiro/93, respectivamente nas áreas Sul e Norte (Fig. 4).

A distribuição de freqüência relativa de machos e fêmeas capturados, durante o período de estudo, apresenta incremento mensal na abundância de $P$. paulensis a partir de agosto/92 até fevereiro/93 (Fig. 3). O teste do $\mathrm{x}^{2}$ indicou diferenças significativas $(\mathrm{p} \leq 0,05)$ a favor das fêmeas nos meses de outubro/92 e fevereiro/93 (Fig. 3). Nos demais meses, foi observada a proporção sexual esperada de 1:1.

Analisando-se a distribuição espacial do camarão-rosa na Lagoa da Conceição ao longo do ano, verifica-se que maiores concentrações ocorreram na área Central seguida da Norte e Sul (Fig. 4). Os teores de salinidade da lagoa oscilam em função do ciclo de maré e do aporte de água doce. Dessa forma, a abundância de $P$. paulensis parece não ser influenciada diretamente pela salinidade. Embora, as maiores freqüências de captura tenham ocorrido no mês de fevereiro/93, nas áreas Norte e Sul com salinidade média entre 17,0 a 20,0\%. Já na área Central, ocorreu em janeiro/93 com salinidade média de 28,5\% (Fig. 4). Para D’InCAO (1991), $P$. paulensis da Lagoa dos Patos (RS), apresenta abundância elevada na faixa de salinidade entre 10,0 a 31,0\%. Comportamento semelhante foi registrado por PÉREZ FARFANTE (1969) e IWAI (1973).

A análise da figura 5 , sugere que abundância de $P$. paulensis na Lagoa da Conceição é regulada, principalmente, pela temperatura ambiente. Dessa forma, as menores freqüências de captura ocorrem no inverno com acréscimo significativo durante a primavera, atingindo o máximo no verão, caindo em seguida durante o outono (Fig. 5). Segundo D'INCAO (1991), as flutuações na abundância de $P$. 
paulensis acompanham a curva de temperatura, com valores mais elevados entre os meses de janeiro a abril. A temperatura média noturna da lagoa apresentou um padrão sazonal bem definido até o mês de novembro/92. Entretanto, as temperatura atípicas registradas durante as coletas dos meses de dezembro/92 a abril/93 podem ter sido causadas pela presença de frentes frias no litoral catarinense.
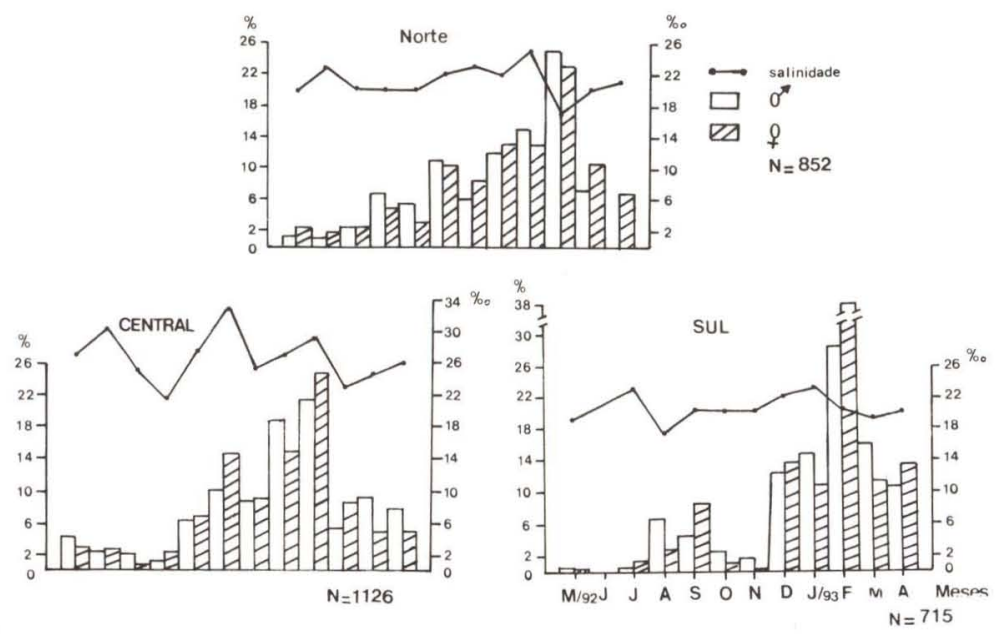

Fig. 4. Penaeus paulensis. Distribuição mensal de frequencia de machos e fêmeas por area de coleta e a flutuaçăo mensal da salınıdade.
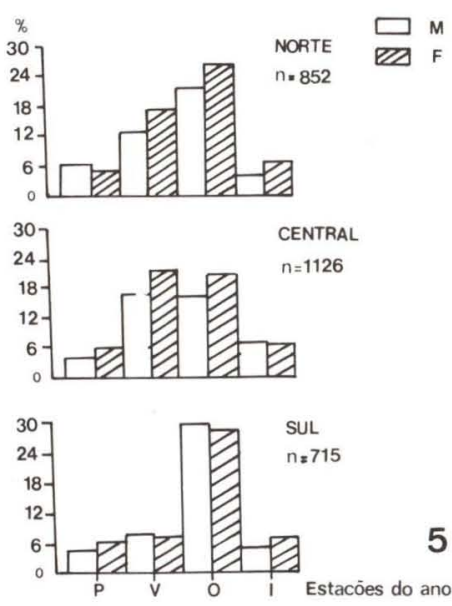
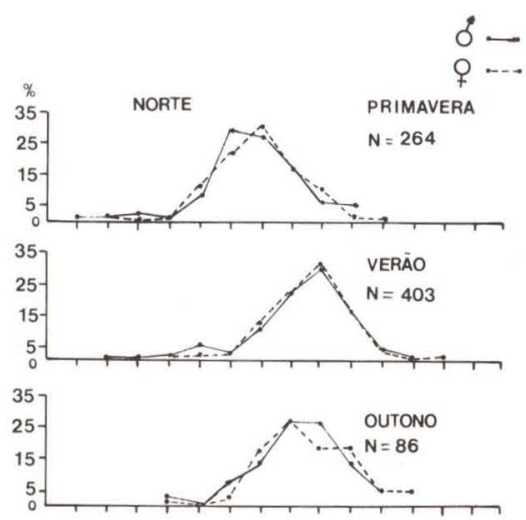

5

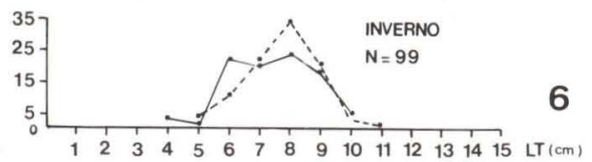

Figs 5-6. Penaeus paulensis. (5) Distribuiçăo sazonal de freqüência de machos e fêmeas, por área de coleta; (6) distribuição de freqüência das classes de comprimento total da área Norte, por estação do ano e sexo. 
As figuras 6,7 e 8 mostram a distribuição das classes de comprimento total de machos e fêmeas, nas três áreas da lagoa. Ocorreram juvenis e pré-adultos de ambos sexos em todas as áreas.

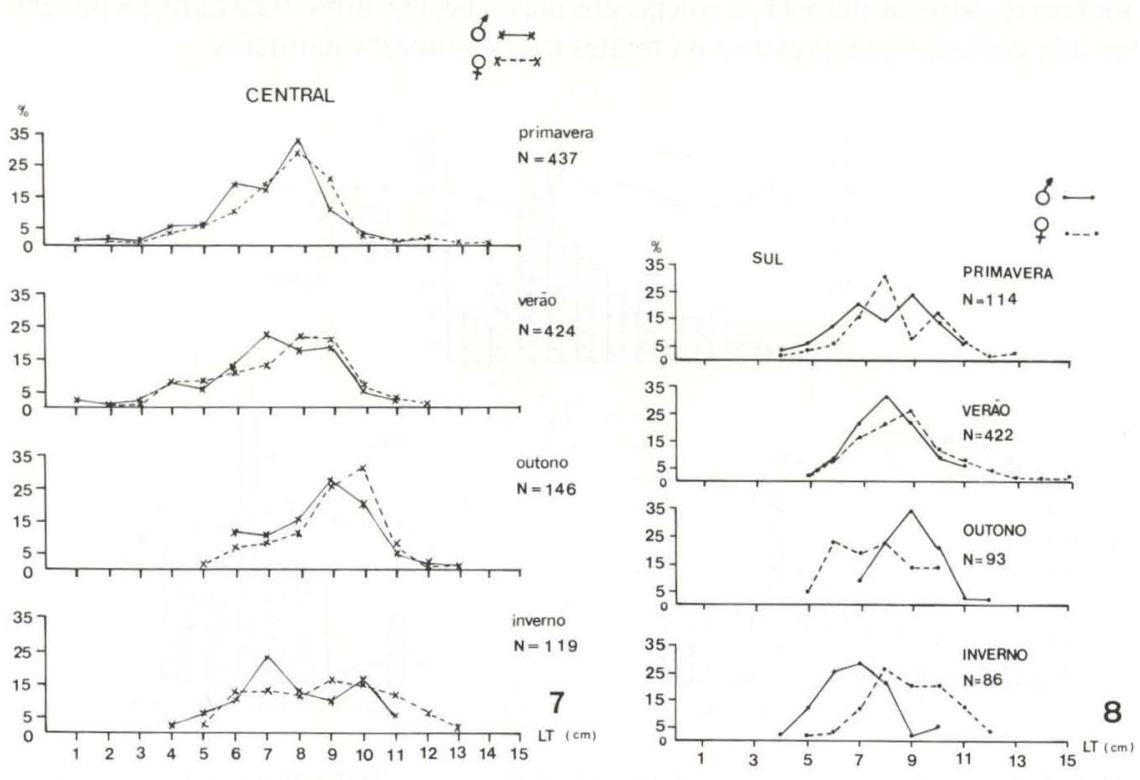

$\mathrm{Na}$ área Norte, a população apresenta-se distribuída entre as classes de 1-2 $\mathrm{cm}$ a $12-13 \mathrm{~cm}$. Durante a primavera, as classes mais freqüentes foram entre $6,0 \mathrm{a}$ $8,0 \mathrm{~cm}$. No verão, ocorreu um incremento significativo na população, principalmente entre as classes de 8,0 a $10,0 \mathrm{~cm}$. No outono, houve queda abrupta na freqüência de camarões e na sua amplitude de tamanho, retrocedendo o deslocamento das classes modais. No inverno, ocorreu pequeno incremento na população da área Norte, destacando-se as classes de 6,0 a 8,0 cm nos machos e de 7,0 a 9,0 cm nas fềmeas (Fig. 6).

$\mathrm{Na}$ área Central, a população $P$. paulensis ocorreu entre as classes de $1-2 \mathrm{~cm}$ a 13-14 cm. Na primavera, as maiores freqüências foram registradas entre as classes de 6,0 a $8,0 \mathrm{~cm}$ nos machos e de 7,0 a 9,0 cm nas fêmeas. No verão, o número de exemplares capturado equiparou-se ao da primavera, sendo que as maiores freqüências foram registradas entre as classes de 7,0 a $9,0 \mathrm{~cm}$. No outono, ocorreu uma queda significativa na freqüência e amplitude de tamanho dos camarões, destacando-se as classes de 9,0 a 10,0 cm. No inverno, a abundância foi relativamente inferior a do outono, sendo que as maiores concentrações de machos ocorreram entre as classes de 7,0 a 10,0 cm e de fêmeas entre 8,0 a $11,0 \mathrm{~cm}$ (Fig. 7).

$\mathrm{Na}$ área Sul, a população do camarão-rosa apresenta-se distribuída entre as classes de $4-5 \mathrm{~cm}$ a $14-15 \mathrm{~cm}$. Durante a primavera, a abundância esteve baixa, se comparada as das áreas Central e Norte. Os machos dessa área, foram mais 
freqüentes entre as classes de 7,0 a 9,0 cm e as fêmeas entre 7,0 a 10,0 cm. No verão, a população apresenta um incremento significativo na abundância, equiparando-se as outras áreas da lagoa, as classes 7,0 a 9,0 cm apresentaram as maiores freqüências. No outono, declina consideravelmente, observando-se a menor amplitude de comprimento nas fêmeas com as maiores freqüência em torno de 6,0 a $8,0 \mathrm{~cm}$ e de 8,0 a $10,0 \mathrm{~cm}$ nos machos.

No inverno, ocorreu a menor abundância na área Norte com domínio dos machos entre as classes de 6,0 e 7,0 cm e das fêmeas entre 8,0 a 10,0 cm (Fig. 8).

O tamanho de pré-adulto foi estimado em $8,8 \mathrm{~cm}$ para as fêmeas e $9,3 \mathrm{~cm}$ para os machos. A partir do comprimento total de $11,5 \mathrm{~cm}$, todos os camarões coletados eram pré-adultos (Fig. 9).

Analisando-se a população de $P$. paulensis da Lagoa da Conceição em função do tamanho de pré-adulto, verifica-se que o esforço de pesca está concentrado, principalmente, sobre os juvenis (machos $=76,8 \%$ e fêmeas $=72,1 \%$ ) é pequena a parcela de pré-adultos (machos $=23,2 \%$ e fêmeas $=27,9 \%$ ) (Fig. 10). Considerando os eventos do ciclo de vida da espécie, a concientização dos pescadores artesanais, a carência de dados sobre o esforço de pesca e a atividade turística da região, pode-se esperar um declínio significativo na abundância, comprometendo a pesca de camarão na lagoa e área Costeira.

Os valores do peso total foram lançados em gráfico em função do comprimento total, para sexos separados, os quais foram corroborados pela linearidade das relações (Fig. 11a,b) e pelos valores do coeficiente de correlação linear de Pearson (r). Mello (1973), trabalhando com camarão-rosa capturados em mar aberto e desembarcados em Santos (SP), obteve os seguintes resultados para a relação peso/comprimento total de $P$. paulensis: machos $\mathrm{Wt}=0,0106 \mathrm{Lt}^{2,87}$, fêmeas $\mathrm{Wt}=$ $0,0108 \mathrm{Lt}^{2,90}$. ZENKER \& AGNES (1977), analisando a distribuição de $P$. paulensis ao longo da costa Sudeste e Sul do Brasil, obtiveram para as relações peso/comprimento do cefalotórax (igual da carapaça) os seguintes resultados: machos $\mathrm{Wt}=1,54$. $10^{-3} \mathrm{Lc}^{2,79}$, fêmeas $\mathrm{Wt}=2,08 \cdot 10^{-3} \mathrm{Lc}^{2,69}$. D'InCAO \& CALAZANS (1978), encontraram para as relações peso/comprimento do cefalotórax de $P$. paulensis da Lagoa dos Patos (RS): machos $\mathrm{Wt}=4,418 \cdot 10^{-4} \mathrm{Lc}^{3,1666}$, fêmeas $\mathrm{Wt}=6,106 \cdot 10^{-6} \mathrm{Lc}^{3,044}$. As equações obtidas para a população da Lagoa da Conceição foram: machos Wt $=0,0098 \mathrm{Lt}^{2,8853}$, fêmeas $\mathrm{Wt}=0,0172 \mathrm{Lt}^{2,6140}$. Comparando os valores de "b" com os obtidos pelos autores acima mencionados, verifica-se que a população da Lagoa dos Patos apresenta um ritmo de crescimento em peso superior ao de outras áreas.

D'INCAO \& CALAZANS (1978), trabalharam com camarões nas fases de crescimento de juvenis e pré-adultos, onde as taxas de crescimento devem ser mais aceleradas. Já os resultados de MELLO (1973) e ZENKER \& AGNES (1977) foram baseados em indivíduos adultos com crescimento relativamente lento. Nossos resultados, embora inferiores aos de D'INCAO \& CALAZANS (1978), que trabalharam com exemplares da Lagoa dos Patos, mas extrapolaram para região oceância, sugerem essa tendência.

A relação comprimento da carapaça/comprimento total foi determinada para machos e fêmeas (Figs 12,13). Considerando que ocorre dimorfismo sexual quanto ao tamanho e a existência de relação linear pela origem, demonstrado nas expressões: A) machos $\mathrm{Lc}=0,2076 \mathrm{Lt}, \mathrm{r}=0,8684$; B) fềmeas $\mathrm{Lc}=0,2085 \mathrm{Lt}, \mathrm{r}=0,8307$. 

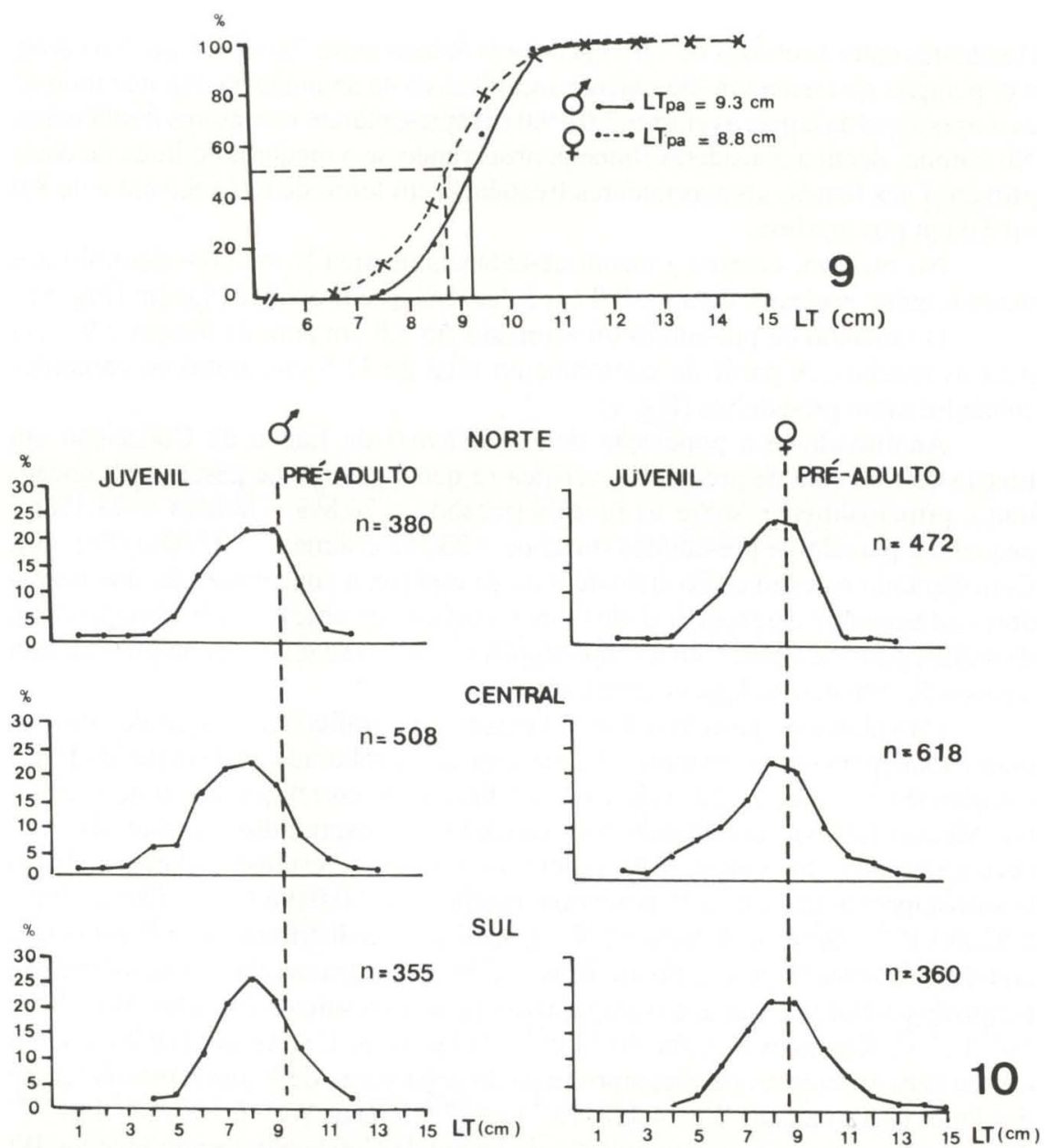

Figs 9-10. Penaeus paulensis, distribuição de freqüências. (9) De machos e fêmeas pré-adultos, por classes de comprimento total; (10) das classes de comprimento total, por área de coleta e sexo.

As expressões representam o crescimento relativo entre Lc e Lt e a constante de regressão corresponde ao índice biométrico. Na prática, o índice biométrico permite estimar o valor de uma variável através do conhecimento da outra. Para determinado comprimento total, corresponderá um comprimento de carapaça, geralmente maior nas fêmeas que nos machos.

As curvas de crescimento em comprimento total $(\mathrm{cm})$ são descritas pelas equações: A) machos $\mathrm{Lt}=12,8\left[1-\mathrm{e}^{-0,2309 \mathrm{t}}\right]$; B) fêmeas $\mathrm{Lt}=14,2\left[1-\mathrm{e}^{-0,1995 \mathrm{t}}\right]$

Nas figuras 14a,b encontram-se as curvas teóricas de crescimento em comprimento ajustadas aos pontos empíricos para machos e fêmeas. 

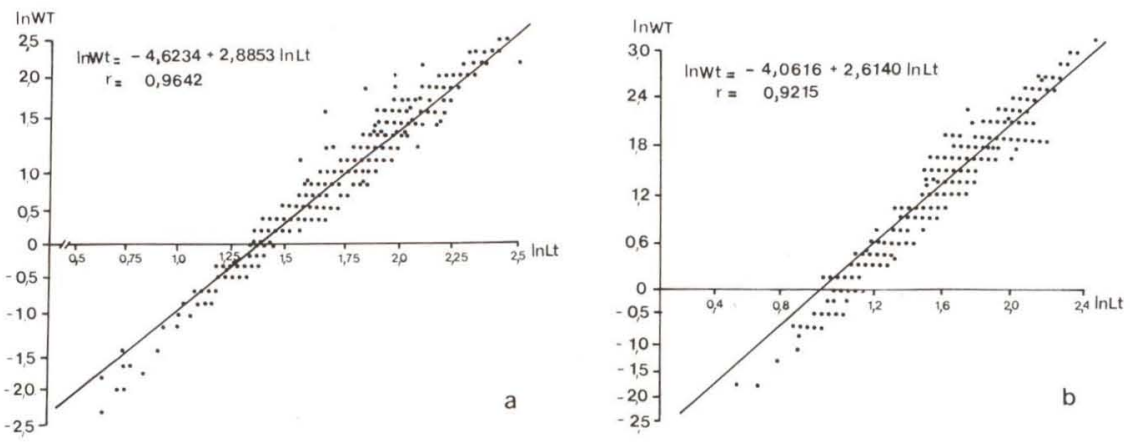

Fig. 11. Penaeus paulensis. Transformação logaritmica da relação peso/comprimento total dos machos (a) e da relação peso/comprimento total das fêmeas (b).
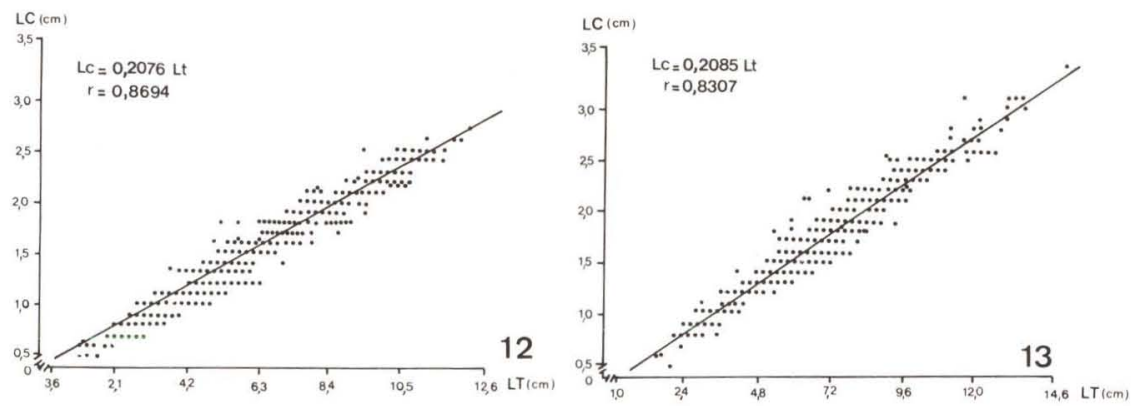

Figs 12-13. Penaeus paulensis, relaçäo entre o comprimento total (Lt) e o comprimento da carapaça (Lt). (12) Machos; (13) fêmeas.

Penaeus paulensis apresenta constante catabólica elevada, sendo que o comprimento total médio observado na população da Lagoa da Conceição é atingindo em torno dos 12 meses de idade.

O crescimento em comprimento da carapaça $(\mathrm{mm})$ foi estimado, a partir das relações entre os índices biométricos e os valores de L $\infty$ das equações de crescimento em comprimento total, resultando nas seguintes expressões: A) machos $L c=26,5\left[1-\mathrm{e}^{-0,2309 \mathrm{t}}\right]$; B) fêmeas $\mathrm{Lc}=29,6\left[1-\mathrm{e}^{-0,1995 \mathrm{t}}\right]$.

Em geral, as fêmeas crescem mais lentamente, atingindo comprimento máximos, em média, maiores que os machos. Essa tendência parece ser um padrão para as populações de P. paulensis da costa Sudeste-Sul do Brasil (MELlo 1973; D'InCaO \& Calazans 1978; D'InCaO 1984). Segundo Garcia \& Le Reste (1981) in D'INCAO (1984), os camarões penaeídeos machos, apresentam constantes de catabolismo (k) mais elevadas que as fêmeas e comprimentos assintóticos menores.

Mello (1973), estudando exemplares adultos de origem oceânica, obteve comprimento assintótico total de $16,5 \mathrm{~cm}$ nos machos e de 21,5 cm nas fêmeas, com 
idade de 30 meses. D'InCAO \& CAlaZAns (1978), trabalhando com camarões juvenis e pré-adultos da Lagoa dos Patos, obtiveram comprimento assintótico de carapaça de $28,7 \mathrm{~mm}$ e $34,6 \mathrm{~mm}$, respectivamente para machos e fêmeas. Embora, os autores tenham considerado esses valores subestimados devido a migração dos exemplares de maior porte para o oceano. Já para D'INCAO (1984), o calado da embarcação utilizada no trabalho anterior, limitou a atividade de pesca a profundidades maiores de um metro, diminuindo muito a área amostrada. Assim, realizou novo estudo na Lagoa dos Patos, obtendo comprimento assintótico de carapaça de 42,02 $\mathrm{mm}$ para machos e 55,64 mm para fềmeas, considerados adeguados segundo à literatura.

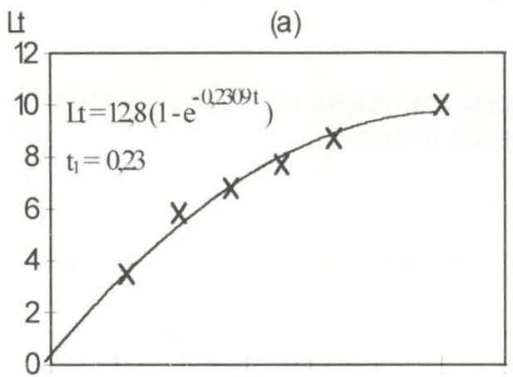

$\begin{array}{lllllll}2 & 4 & 6 & 8 & 10 & 12 & 14\end{array}$
Lt

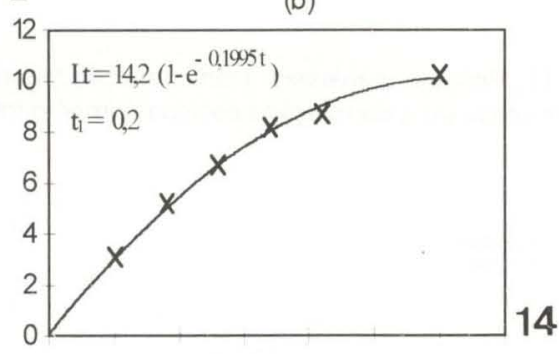

$\begin{array}{lllllll}2 & 4 & 6 & 8 & 10 & 12 & 14 \\ \text { Meses }\end{array}$
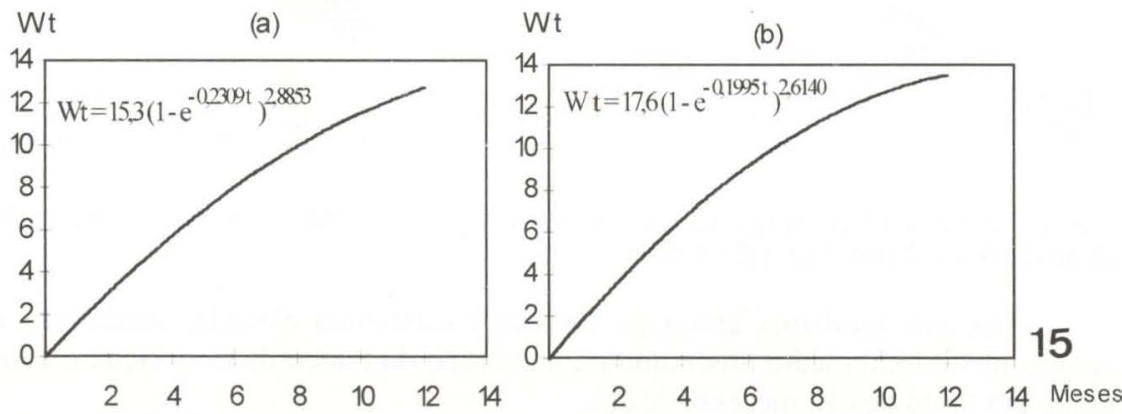

Figs 14-15. Penaeus paulensis machos (a) e fêmeas (b). (14) Curva de crescimento em comprimento total; (15) curva de crescimento em peso.

$\mathrm{O}$ crescimento em peso de $P$. paulensis encontra-se representado nas figuras $15 \mathrm{a}, \mathrm{b}$ cujas curvas apresentam as seguintes expressões: A) machos $\mathrm{Wt}=15,3[1-$ $\left.\left.\mathrm{e}^{-0,2309 \mathrm{t}}\right]^{2,8852} ; \mathrm{B}\right)$ fêmeas $\mathrm{Wt}=17,6\left[1-\mathrm{e}^{-0,1995 \mathrm{t}}\right]^{2,6140}$.

Os machos atingem, em média, menor peso que as fêmeas para uma mesma classe de comprimento. Esse comportamento segue o padrão registrado pelos autores acima citados.

Segundo D'INCAO (1991), os camarões do gênero Penaeus apresentam um ciclo de vida relativamente curto, variando entre 16 a 30 meses. Considerando o número pequeno de exemplares capturados na Lagoa da Conceição com comprimento entre 13,0 cm (machos) e 15,0 cm (fêmeas) para caracterizar uma classe 
modal. Os comprimentos e pesos totais assintóticos para uma idade de 30 meses parecem subestimados, devido à ausência de dados da área oceânica, onde ocorre a reprodução e continuação do crescimento em ritmo lento.

Para D'INCAo (1991), P. paulensis da Lagoa dos Patos com idade a partir de 5 meses nos machos e quatro meses nas fêmeas, que correspondem a comprimentos totais entre 7,0 e $8,0 \mathrm{~cm}$, podem iniciar sua migração para o oceano. Embora, alguns exemplares podem permanecer na lagoa até a idade de 10 meses.

Assumindo que o principal pulso de penetração das pós-larvas de $P$. paulensis na Lagoa da Conceição seja semelhante ao da Lagoa dos Patos, entre os meses de agosto e novembro (BARCELLOS 1968). Exemplares com comprimento total entre 1,0 a 3,0 cm e idade aproximada de dois meses aparecem nas áreas Central e Norte no final da primavera-início do verão, provavelmente transportados pela ação da maré e de ventos. Exemplares a partir dos $6,0 \mathrm{~cm}$ de comprimento, são comuns na lagoa durante $\mathrm{o}$ ano. $\mathrm{O}$ tamanho de pré-adulto foi estimado em $8,8 \mathrm{~cm}$ para fêmeas e $9,3 \mathrm{~cm}$ para machos, quando, em média, possuem entre 9 a 10 meses de idade. Coincide com as maiores freqüências de camarões entre as classes de 7,0 a $10,0 \mathrm{~cm}$. A redução drástica na abundância registrada em meados do outono início do inverno, sugere migração para o oceano. Embora, alguns indivíduos com comprimentos superior a 10,0 cm, permaneçam na Lagoa da Conceição.

Os resultados das curvas de crescimento em comprimento e peso, bem como, dos comprimentos e idades de migração, obtidos a partir do deslocamento das modas em função do tempo (SANTOS 1978), não puderam ser comparados com os registrados para Lagoa dos Patos por D'INCAO (1984) e reapresentados em 1991, como parte da síntese de conhecimento sobre pesca e biologia de $P$. paulensis, devido à metodologia empregada na obtenção das modas. Entretanto, é provável que os migrantes da Lagoa da Conceição, possam com 30 meses de idade, alcançar tamanhos semelhantes aos da literatura.

AGRADECIMENTOS. Aos colegas Marcelo Gentil Avila e Márcio Guilherme Bosco Westphal, pelo valioso auxílio nos trabalhos de campo e laboratório. De forma especial, aos Consultores anônimos da RBZ que contribuiram na apresentação deste trabalho.

\section{REFERÊNCIAS BIBLIOGRÁFICAS}

BARCELLOS, B.N. 1968. Resultados preliminares da pesca exploratória de camarões na costa do Rio Grande do Sul. I. Bol. Inform. Ind. Pesca, São Paulo, (1): 1-19. BertalanfFy, L.V. 1938. A quantitative theory of organic growth. Hum. Biol. 10 (2): 181-213.

D'INCAO, F. 1984. Estudo sobre o crescimento de Penaeus (Farfantepenaeus) paulensis Pérez Farfante, 1967 da Lagoa dos Patos, RS, Brasil (Decapoda, Penaeidae) Atlântica, Rio Grande, 7: 73-84.

- 1991. Pesca e biologia de Penaeus paulensis na Lagoa dos Patos, RS. Atlântica, Rio Grande, 13 (1): 159-169.

D'INCAO, F. \& D.K. CALAZANS. 1978. Relações biométricas do "camarão rosa" Penaeus paulensis Pérez Farfante, 1967 na Lagoa dos Patos, RS, Brasil. Atlân- 
tica, Rio Grande, 3: 57-66.

GAMBA, M.R.; M.A. BAILON \& P.C. CONOLLY. 1993. Catálogo das artes de pesca artesanal do Estado de Santa Catarina. Itajaí, Cepsul-Ibama, 119p.

HolthUIS, L.B. 1980. Shrimps and prawns of the world and annoted catalogue of species of interest to fisheries. FAO Fish. Synopsis, 125 (1): 1-271.

IWAI, M. 1973. Pesquisa e estudo biológico dos camarões de valor comercial. Publ. esp. Inst. Oceanogr., São Paulo, 3 (1): 501-534.

MELLO, J.T.C. 1973. Estudo populacional do "camarão-rosa" Penaeus brasiliensis (Latreille, 1817) e Penaeus paulensis Pérez Farfante 1967. Bol. Inst. Pesca, São Paulo, 2 (2): 19-65.

NAscimento, P.A.M.; G.S. RuPP; R.G. LOPES; A.P. LuZ \& J.M. BITTENCOURT. 1985. Camarões de interesse comercial das águas de Santa Catarina. In: Anais do I Seminário sobre ciências do mar da Universidade Federal de Santa Catarina (1): 42-45.

PÉRez Farfante, I. 1969. Western Atlantic shrimps of the genus Penaeus. Fish. Bull. 67 (3): 461-591.

1970. Diagnostic characters of juveniles of the shrimps Penaeus aztecus aztecus, $P$. duorarum duorarum, and $P$. brasiliensis (Crustacea, Decapoda, Penaeidae). Spec. Sci. Rep. Fih. 599: 1-26.

SANTOS, E.P. 1978. Dinâmica de populações aplicada à pesca e piscicultura. São Paulo, Hucitec, Edusp, 129p.

VAlentini, H.; F. D'InCAO; L.F. RodRigues; J.E. Rebelo Neto \& E. RAHN. 1991. Análise da pesca do camarão-roda (Penaeus brasiliensis e Penaeus paulensis) nas regiões Sudeste e Sul do Brasil. Atlântica, Rio Grande, 13 (1): 143-157.

VAZZOLER, A.E.A. DE M. 1981. Manual de métodos para estudos biológicos de populações de peixes: reprodução e crescimento. Brasília, CNPq, Programa Nacional de Zoologia, 106p.

WALFORD, L.A. 1946. A new graphic method of describing the growth of animals.

Biol. Bull. 90 (2): 141-147.

ZENKER, H.H. \& J.L. AgNeS. 1977. Distribuição do camarão rosa Penaeus brasiliensis e Penaeus paulensis ao longo da costa Sudeste e Sul do Brasil. Sér. Doc. Tec., Sudepe-PDP, Brasília, 21: 1-105.

Recebido em 16.I.1997; aceito em 15.V.1998. 